\title{
Low temperature behavior of asphaltite modified binders and asphalt concretes
}

\author{
Andrea Themeli, ${ }^{1, *}$, Emmanuel Chailleux ${ }^{2}$, Cyrille Chazallon ${ }^{3}$, Nicolas Bueche ${ }^{1}$ \\ ${ }^{1}$ Bern University of Applied Sciences, Dpt. Architecture, Wood and Civil Engineering, \\ Pestalozzistr. 20,3400 Burgdorf, Switzerland.andrea.themeli@bfh.ch, nicolas.bueche@bfh.ch \\ 2 LUNAM Univ., IFSTTAR, MAST, MIT, Route de Bouaye, BP 4129, F-44341 Bouguenais, \\ France.emmanuel.chailleux@ifsttar.fr \\ ${ }^{3}$ ICUBE (UMR 7357, CNRS, National Institute of Applied Sciences), 24, Bd. de la Victoire, F- \\ 67084 Strasbourg Cedex, France. cyrille.chazallon@insa-strasbourg.fr
}

\begin{abstract}
Natural asphalts are often used as stiffeners to obtain hard bitumens. With the decrease of the global production of hard bitumens, the use of natural asphalts as stiffeners becomes increasingly interesting. The main concern when natural asphalts are used as modifiers, is the behavior at low temperature. Studies have shown a brittle behavior in the low temperature domain, especially when high-content-asphaltene natural asphalts, like the Gilsonite, are used. In the context of a wider study, carried out in IFSTTAR, we have tested the low-temperature behavior of asphaltite modified bitumens and that of corresponding asphalt concretes. The Selenizza ${ }^{\circledR}$ asphaltite is used at 5, 10 and $15 \%$ to modify a pure petroleum bitumen of 50/70 penetration grade. Asphalt concretes of type EME were then produced. 3P bending tests on notched bitumen bars were performed in order to assess the cracking temperature of binders. On the asphalt concrete scale, thermal stress restrain tests and traction resistance tests at low temperatures were carried out in order to assess the low temperature behavior. Equivalent materials (pure refinery binders and EME produced with hard petroleum binder) were also tested in order to have references. Compared to these equivalent materials, the asphaltite stiffened materials (asphaltite modified bitumens and corresponding asphalt concretes) present comparable, and in some cases, better low temperature behavior.
\end{abstract}

Keywords: Low temperature behavior of binders and asphalts; Natural bitumen; Asphaltite modified bitumens; High modulus asphalt concrete.

\section{Introduction}

Hard bitumens are of real interest in pavement engineering nowadays. They are used in the production of high modulus asphalt concretes (HMAC). HMAC allow the reduction of thickness of structural pavement layers and/or the prolongation of the pavement lifetime $[\underline{1} 1, \underline{2} 2]$.

Hard bitumens are produced in petrol refineries by processing the residue of the vacuum distillation of petrol by means of different techniques as air blowing, oxidation, solvent deasphalting etc. [33] ]. Hard bitumens are lacking also in and 
appeals are made to the careful use of this material [44]. For these reasons, several studies aim to develop alternatives for the production of hard bitumens.

These alternatives very often consist in the modification of soft petroleum bitumens by various modifiers [ $[5]$ ]. Several researchers have studied the impact on the composition and on the mechanical properties of various bitumen modifiers [661111].

Asphaltites have a good potential for the production of hard pavement bitumens. Asphaltites are hard natural bitumens and are chemically similar to petroleum bitumens. In a wider work [1212], the authors of this paper have shown that the asphaltite modification of pure petroleum bitumens lightly affect their chemical composition in terms of SARA fractions and molecular associations determined by GPC. But the mechanical behavior is strongly affected [1313, 1414].

One of the main concerns, when using asphaltites as modifiers the bitumens, is the behavior at the low temperatures (LT). In general, hard bitumens and the corresponding asphalt concretes are susceptible to show a brittle behavior at LT.

The natural asphaltite used in this study is mined in Albania in the region of Selenizza. The asphaltite modification of soft petroleum bitumens gives hard binders. With these binders, HMACs which satisfy the European standards can be obtained. However, we do not know how asphaltite modified bitumens and asphaltite modified HMACs behave at LT. So, the scope of the work presented in this work is to study the LT behavior of Selenizza ${ }^{\circledR}$ modified bitumens and HMACs. The LT behavior of modified bitumens is studied by a three-point bending test performed on notched bitumen bars. The LT behavior of HMACs is studied by thermal stress restrained specimen test (TSRST) combined with uniaxial tension stress test (UTST). In addition, the results are compared with theosem of equivalent materials (pure petroleum bitumen and HMAC produced with hard petroleum bitumen). This allows to make relevant comparisons and to draw clear conclusions on whether asphaltite modified bitumens can substitute or not hard petroleum bitumens as binders for HMAC production.

\section{Experimental}

\subsection{Tests on modified bitumens}

3P bending test on notched bitumen bars are performed on aged bitumens.

\subsubsection{Ageing procedure}

PAV ageing for 25 hours at $100^{\circ} \mathrm{C}$ and under a pressure of $2.1 \mathrm{MPa}$ are applied. The additional 5 hours compared to a standard PAV test (which takes 20h) allow to skip the RTFOT tests normally performed before PAV. Indeed, it has been shown that $5 \mathrm{~h}$ 
of PAV exposition give an aged bitumen with penetrability, $R \& B$, asphaltene percentage, creep and complex modulus equivalent to those of bitumens submitted the RTFOT ageing [1515]. Extended PAV tests are often used in the literature [1616].

\subsubsection{Test for the low temperature crack behavior}

The LT mechanical behavior of bitumens is studied with a 3P bending test on notched bitumen bars. The test is based on the principles of fracture mechanics adapted for bitumens [1717-1919]. The test geometry is optimized [2020, 2121] (Fig. 1Fig. 1) and a viscoelasticity analysis is used to interpret the results [22z2].

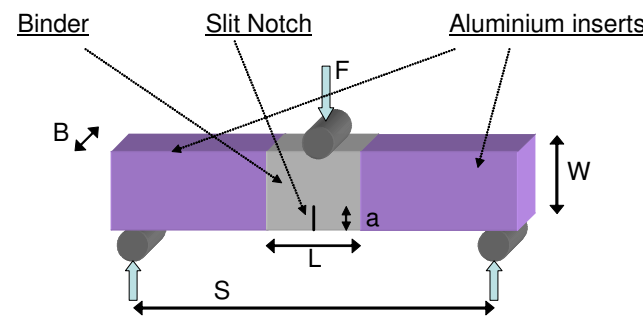

(a)

\begin{tabular}{|l|}
\hline Dimensions : \\
$\mathrm{B}=12,5 \mathrm{~mm}$ \\
$\mathrm{~S}=100 \mathrm{~mm}$ \\
$\mathrm{~W}=25 \mathrm{~mm}$ \\
$\mathrm{~L}=40 \mathrm{~mm}$ \\
$\mathrm{a}=5 \mathrm{~mm}$
\end{tabular}

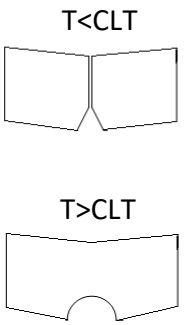

(b)

Fig. 1: 3P bending test on notched bar: (a) geometry, (b) failure modes.

A notch is created in the material to trigger the failure in mode I. The test is carried out in a bath of water and potassium acetate (concentration 42\%) at constant temperatures. A vertical displacement, of constant speed $0.01 \mathrm{~mm} / \mathrm{s}$, is applied at the mid-length of the beam and the resulting force is recorded.

Depending on the test temperature, the specimen presents a fragile crack or an excessive plastic deformation without (Fig. 1Fig. 1b). The cracking limit temperature (CLT), which corresponds to the temperature below which the sample presents a fragile rupture, defines the transition between the fragile and non-fragile state. The test is very sensitive to the temperature and allows to determine the CLT to the degree, i.e. if the TLF is $3^{\circ} \mathrm{C}$, the sample always cracks at $3^{\circ} \mathrm{C}$ and not at $4^{\circ} \mathrm{C}$.

The test allows to calculate the critical energy recovery rate $\left(G_{C}\right)$ at failure. Its value, derived from a viscoelasticity analysis [22z2] is given by the expression:

$$
G_{C}=409,7 \cdot F_{u} \cdot d_{u}
$$

where $F_{u}$ and $d_{u}$ are the force and the deformation at the failure moment.

\subsection{Tests on HMAC}


The LT behavior of HMAC is determined by thermal stress restrained specimen tests (TSRST) combined with uniaxial tension stress test (UTST) according to the European standard EN 12697-46. These tests allow the calculation of the tensile strength reserve.

\subsubsection{UTST}

The specimen maintained at constant temperature is subjected to a tensile stress with a constant deformation rate of $0.625 \pm 0.025 \% / \mathrm{min}$ until failure. The test results are expressed as tensile resistance $\beta_{t}(T)$ and deformation at rupture $\varepsilon_{\text {failure }}(T)$. Different specimens of the same material are to be tested at different temperatures. The results are reported on a temperature-resistance diagram. The test results at different temperatures are fitted by a cubic polynomial function.

\subsubsection{TSRST}

The sample maintained at a constant length is subjected to a constant decrease in temperature of $10^{\circ} \mathrm{C} / \mathrm{min}$. Due to the restrained shrinkage, cryogenic stress develops in the specimen. The test results are the evolution of cryogenic stress as a function of temperature $\sigma_{c r y}(T)$, the ultimate stress $\sigma_{\text {cry,failure }}$ and failure temperature, $T_{\text {failure }}$.

\subsubsection{Tensile strength reserve}

The tensile strength reserve expresses the decrease in the mechanical tensile strength due to the presence of thermal tensile stresses. At a given temperature $T$ the strength reserve is given by the expression:

$$
\Delta \beta_{t}(T)=\beta_{t}(T)-\sigma_{c r y}(T)
$$

with $\beta_{t}(T)$ the tensile resistance and $\sigma_{c r y}(T)$ the cryogenic stress at temperature $T$ determined respectively by means of UTST and TSRST.

\section{Materials}

\subsection{Bitumens}

The bitumens considered in this study are presented in the Table 1Table 1.

Table 1: Bitumens considered in this study.

\begin{tabular}{llcc}
\hline Reference & Description & $\begin{array}{c}\text { Pen. } \\
(\mathrm{dmm})\end{array}$ & $\begin{array}{c}\text { R\&B } \\
\left({ }^{\circ} \mathrm{C}\right)\end{array}$ \\
\hline Selenizza ${ }^{\circledR}$ & Organic phase of asphaltite extracted in deep layers of the mine & NA & 120 \\
P50/70 & Petroleum bitumen of $\mathbf{5 0 / 7 0}$ grade to be modified & 54 & 49.0 \\
\hline
\end{tabular}




\begin{tabular}{llll}
\hline P35/50 & Petroleum bitumen of 35/50 grade used for comparison & 44 & 56.4 \\
$5 \%$ AS+95\%P50/70 & $\mathbf{5 0 / 7 0}$ grade petroleum bitumen modified with 5\% of Selenizza ${ }^{\circledR}$ & 38 & 52.6 \\
$10 \%$ AS+90\%P50/70 & $\mathbf{5 0 / 7 0}$ grade petroleum bitumen modified with 10\% of Selenizza ${ }^{\circledR}$ & 28 & 56.2 \\
15\%AS+85\%P50/70 & $\mathbf{5 0 / 7 0}$ grade petroleum bitumen modified with 15\% of Selenizza ${ }^{\circledR}$ & 20 & 61.6 \\
\hline
\end{tabular}

\subsubsection{The asphaltite}

The asphaltite is mined in Albania in the region of Selenizza. In its natural state it contains $15-18 \%$ of fine mineral material. The organic phase, which is used to modify the petroleum bitumens, is isolated by dissolution in tetrachloroethylene and filtercentrifugation. The composition and some basic properties of the asphaltite are given in Table 2Table 2 in comparison with the properties of the petroleum bitumen P50/70 and the properties of the Gilsonite. The SARA fractions, the FTIR indices, the agglomerate contents and the glass transition temperatures are determined according to methods explained by Le Guern et al. [1616].

Table 2: Characteristics of Selenizza ${ }^{\circledR}$ asphaltite; comparison with other materials

\begin{tabular}{|c|c|c|c|c|}
\hline \multicolumn{2}{|c|}{ Test } & Selenizza $^{\circledR}$ & P50/70 & $\begin{array}{c}\text { Gilsonite } \\
\text { [2323] }\end{array}$ \\
\hline \multirow{2}{*}{$\begin{array}{l}\text { c7 - precipitation } \\
(\text { NF T60-115) }\end{array}$} & Asphaltenes c7 (\%) & 43.8 & 10.2 & \\
\hline & Maltenes (\%) & 56.2 & 89.8 & \\
\hline \multirow{4}{*}{ SARA fractions } & Saturates $(\%)$ & $1.7 \pm 0.35$ & $6.7 \pm 0.65$ & \\
\hline & Aromatics $(\%)$ & $24.8 \pm 2.29$ & $50.5 \pm 1.81$ & $2-6$ \\
\hline & Resins (\%) & $35.1 \pm 1.35$ & $26.1 \pm 1.64$ & $21-37$ \\
\hline & Asphaltenes Iatrosc. (\%) & $38.4 \pm 1.88$ & $16.7 \pm 1.42$ & $57-76$ \\
\hline \multirow{2}{*}{$\begin{array}{c}\text { Oxidation (FTIR } * * \\
\text { indexes) }\end{array}$} & Sulfoxyde & 6.36 & - & \\
\hline & Carbonyl & 3.99 & - & \\
\hline \multicolumn{2}{|c|}{ Agglomerate content (HS-SEC*) $(\%)$} & 2.4 & 0.92 & \\
\hline \multicolumn{2}{|c|}{ Glass transition temperature $\left({ }^{\circ} \mathrm{C}\right)$} & -1.1 & -22.9 & $85-107$ \\
\hline \multicolumn{2}{|c|}{ Penetrability $(0.1 \mathrm{~mm})(\mathrm{EN} 1427)$} & NA & 54 & 0 \\
\hline \multicolumn{2}{|c|}{ R\&B Temperature $\left({ }^{\circ} \mathrm{C}\right)(\mathrm{EN} 1426)$} & 119 & 49 & $129-204$ \\
\hline \multicolumn{2}{|c|}{$\left|\mathrm{E}^{*}\right|\left(15^{\circ} \mathrm{C}, 10 \mathrm{~Hz}\right)(\mathrm{Pa})$} & $1.23 \cdot 10^{9}$ & $1.26 \cdot 10^{8}$ & \\
\hline
\end{tabular}

* High speed size exclusion chromatography. **Fourier transform infrared spectroscopy

\subsubsection{The modified bitumens}

The modifying process consists in adding the fine grained asphaltite $(\Phi<1 \mathrm{~mm})$ in the preheated soft petroleum bitumen P50/70. The blend is carried out by mixing both materials with a high shear mixer for $1 \mathrm{~h}$ at $180^{\circ} \mathrm{C}$. Modification rates of 5, 10 and $15 \%$ are chosen (Table 1). The modified binders get harder with the modification rate. They satisfy the European Norms (EN 12591, EN 13924). 


\subsubsection{The petroleum bitumen P35/50 for comparison}

The petroleum bitumen used for the comparison is found in the database of IFSTTAR. It was chosen to be compared with the $5 \% \mathrm{AS}+95 \% \mathrm{P} 50 / 70$ bitumen because of the rheological similarity between the two bitumens (Fig. 2Fig. 2).
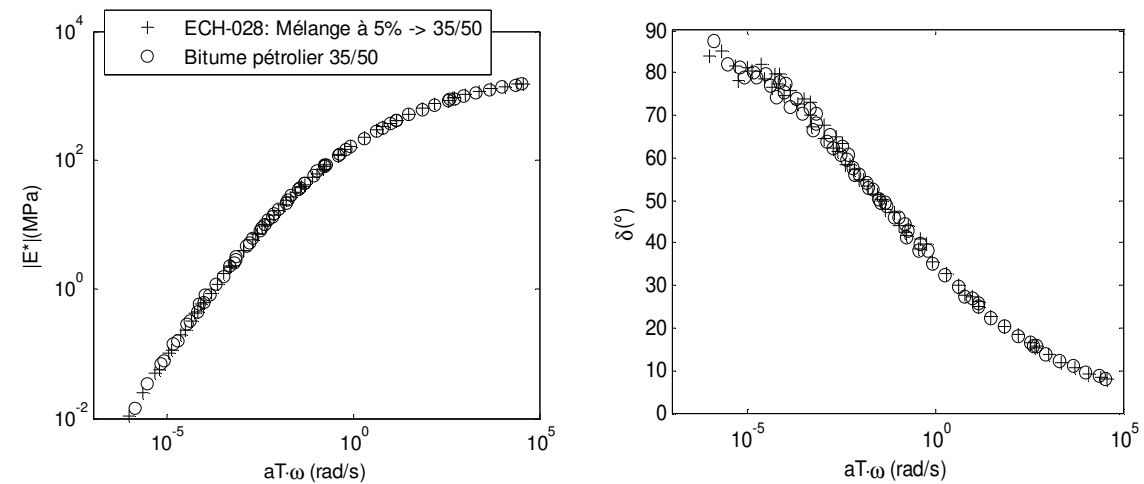

Fig. 2: Complex modulus of the 5\% AS+95\% $50 / 70$ modified bitumen compared to the petroleum bitumen P35/50 (Tref $=0^{\circ} \mathrm{C}$ ): (a) norm of the complex modulus, (b) phase angle.

\subsection{HMACs}

The HMACs considered in this study are given in Table $\mathbf{3}$ Table 3.

Table 3: The HMACs considered in this study.

\begin{tabular}{|c|c|}
\hline Reference & $\begin{array}{l}\text { Description } \\
\end{array}$ \\
\hline EME-01 & HMAC produced with hard petroleum bitumen of penetration grade $20 / 30$ \\
\hline EME-02 & HMAC produced with asphaltite modified ${ }^{a} 50 / 70$ petroleum bitumen \\
\hline EME-03 & $\begin{array}{l}\text { HMAC produced with petroleum bitumen of grade } 50 / 70^{\mathbf{b}} \text { and } \text { asphaltite } \\
\text { added }^{c} \text { in the asphalt mixer }\end{array}$ \\
\hline
\end{tabular}

The comparison of EME-02 with EME-03 allows to study the impact of the mode of introduction of asphaltite on the properties of asphalt mixes. The comparison of these two asphalt mixes with the EME-01 allows to compare the alternative solutions produced with asphaltite, with what is produced with hard petroleum bitumens.

The EME-01 is optimized according to the French method for asphalt concrete design in order to have a HMAC of class 2 . The design is based on gyratory tests, $2 \mathrm{P}$ complex modulus and $2 \mathrm{P}$ fatigue tests. The bitumen content is $5.6 \%$ of the total asphalt mix mass. The EME-02 and the EME-03 have the same constitution as the EME-01 (granulometric curve, bitumen content). The HMACs are produced at $180^{\circ} \mathrm{C}$.

The mixing time for the EME-01 and the EME-02 is as follows: 
- Aggregate homogenization: 30 seconds; Mixing with the binder: 2 minutes The mixing time for the EME-01 and the EME-02 is as follows:

- Aggregate homogenization: 30 seconds; Mixing with crushed asphaltite $(\varnothing \leq 2$ $\mathrm{mm}): 30$ seconds; Mixing time with petroleum bitumen: 2.5 minutes.

\section{Results and discussion}

\subsection{Asphaltite modified bitumens}

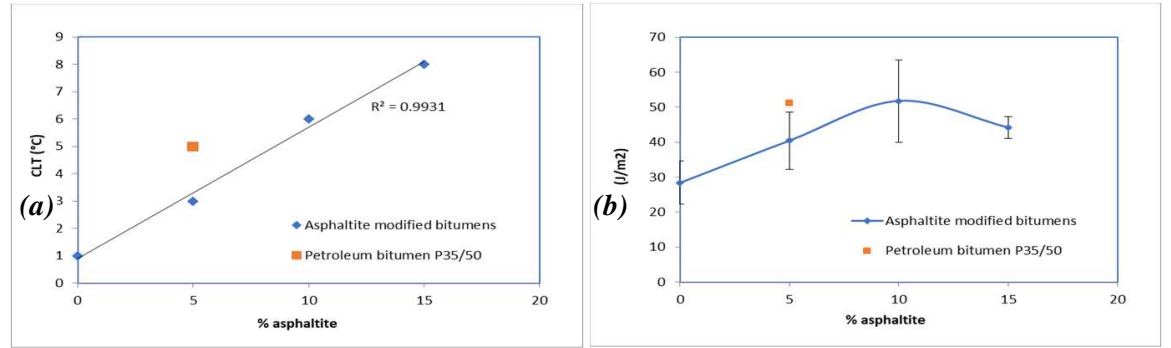

Fig. 3: Evolution of the cracking limit temperature (a) and of the critical energy recovery rate (b).

The evolution of the CLT and of the $G_{C}$ with the asphaltite content are given in Fig. 3Fig. 3. Modified bitumens become more fragile brittle ? with the modification rate. The comparison of the $5 \%$ asphaltite modified bitumen with the petroleum bitumen $35 / 50$ of Fig. 2Fig. 2 shows that the asphaltite modified bitumen is more resistant to cracking (Fig. 3Fig. 3a). It will be interesting in the future to compare the CLTs of the other modified bitumens with petroleum bitumens of equivalent viscoelastic behavior. The trend observed in Fig. 3Fig. 3b seems to show that $10 \%$ of asphaltite is a threshold at which the critical energy recovery rate begins to decrease. However, the error ranges of the measurements do not allow this conclusion to be validated.

\subsection{HMACs}

As stated before, the LT behavior of the HMACs is studied by TSRST and UTST tests. The results of these tests are combined in order to calculate the tensile strength reserve.

\subsubsection{Uniaxial tensile strength (UTST)}



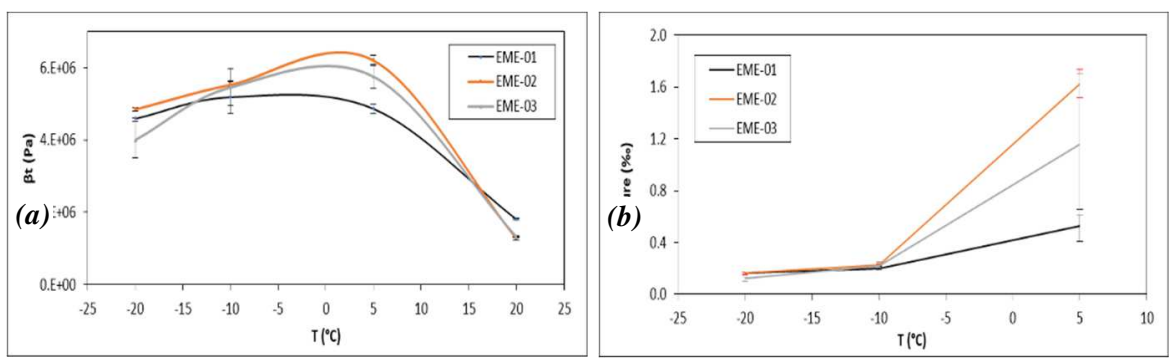

Fig. 4: Uniaxial tensile strength (a) and failure deformation.

The tensile strength is determined at $-20^{\circ} \mathrm{C},-10^{\circ} \mathrm{C}, 5^{\circ} \mathrm{C}$ and $20^{\circ} \mathrm{C}$. The results presented in Fig. 4Fig. 4 show that asphalt mixes with asphaltite (EME-02, EME-03), in the majority of the covered temperature range, have higher tensile strengths than the EME-01 which is produced with $20 / 30$ petroleum bitumen. For example, at $5^{\circ} \mathrm{C}$, the tensile strength of the EME-01, is $4.87 \mathrm{MPa}$, while the tensile strength of EME-02 is $6.06 \mathrm{MPa}$. The results presented in Fig. 4Fig. 4b show that EMEs with asphaltite are more ductile. For example, the EME-02 has a failure deformation of $1.625 \%$ at $5^{\circ} \mathrm{C}$. On the other hand, the failure deformation of the EME- 01 at $5^{\circ} \mathrm{C}$ is $0.528 \%$.

\subsubsection{Thermal stress restrained specimen tests (TSRST)}

The results in Fig. 5 Fig. 5 show that the EME-01 is more thermo-rigid than the EMEs with asphaltites, which perform better at LT. The failure temperature of the EMEs with asphaltite are $3.5-4.5^{\circ} \mathrm{C}$ lower than the failure temperature of the EME-01 (Table 4Table 4). We observe in Table 4Table 4, that for the EME-03, in which the asphaltite is added directly to the asphalt mixer, the deviation of the results is more important. We note the same thing for the UTST results presented in Fig. 4Fig. 4. These observations can be explained by a non-uniform repartition of the asphaltite within the EME-03.
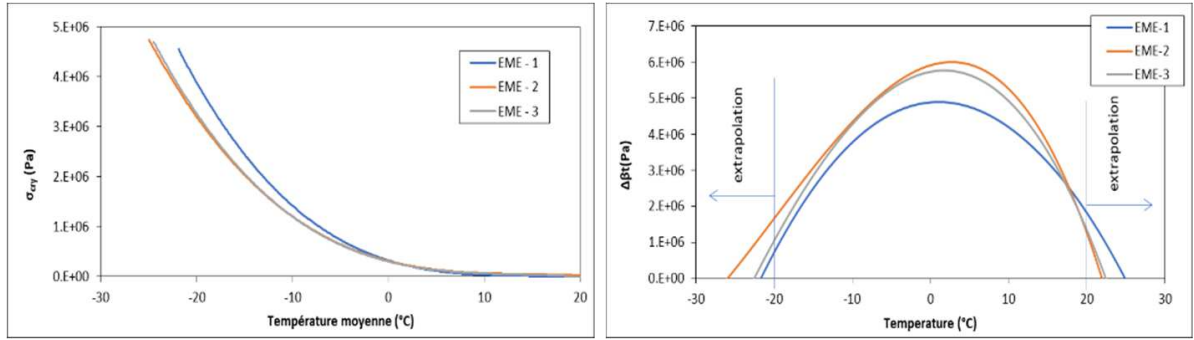

Fig. 5: Thermal stress during TSRST.

Fig. 6: Tensile strength reserve.

Table 4: TSRST results.

\begin{tabular}{|c|c|c|c|c|}
\hline \multirow{2}{*}{ Ref. } & \multicolumn{2}{|c|}{$T_{\text {failure }}\left({ }^{\circ} \mathrm{C}\right)$} & \multicolumn{2}{c|}{$\sigma_{\text {cry,failure }}(\mathrm{MPa})$} \\
\cline { 2 - 5 } & Mean value & Standard deviation & Mean value & Standard deviation \\
\hline EME-01 & $-21,4$ & 0,27 & 4,523 & - \\
\hline EME-02 & $-25,1$ & 0,48 & 4,752 & 0,13 \\
\hline
\end{tabular}




\begin{tabular}{|c|c|c|c|c|}
\hline EME-03 & $-24,9$ & 1,47 & 4,715 & 0,36 \\
\hline
\end{tabular}

\subsubsection{Tensile strength reserve}

The EMEs produced with asphaltite present a higher tensile strength reserve (Fig. 6 Fig. 6). Based on failure temperatures $T_{F}$ and on the other results presented in the Table 5Table 5, the EME-02 presents the best low-temperature performance.

Table 5: Tensile strength reserve characteristics.

\begin{tabular}{|c|c|c|c|c|}
\hline Reference & $T_{F}\left({ }^{\circ} \mathrm{C}\right)$ & $\sigma_{F}(\mathrm{MPa})$ & $T\left(\Delta \beta_{t, \max }\right)$ & $\Delta \beta_{t, \max }$ \\
\hline EME-01 & $-21,7$ & 4,470 & 1,0 & 4,900 \\
\hline EME-02 & $-26,0$ & 5,091 & 2,7 & 6,000 \\
\hline EME-03 & $-22,5$ & 4,021 & 1,8 & 5,759 \\
\hline
\end{tabular}

\section{Conclusions}

The scope of the present paper was to study the LT behavior of Selenizza ${ }^{\circledR}$ modified binders and of HMAC produced with the Selenizza ${ }^{\circledR}$ natural bitumen. The LT behavior of these materials was compared with the behavior of typical materials (hard petroleum bitumens and associated HMAC) actually present in the market and widely used in for road construction. In order to assure a relevant comparison, care was made to choose/produce materials for comparison which are equivalent to the materials obtained by Selenizza ${ }^{\circledR}$ modification. It resulted that:

- The Selenizza gives hard bitumens. A 50/70 bitumen gives 35/50, 20/30 and 10/20 bitumens with 5,10 and $15 \%$ of Selenizza respectively.

- The comparison of the LT behavior of the 35/50 modified bitumen with a 35/50 petroleum bitumen with similar viscoelastic behavior, shows that the Selenizza modified $35 / 50$ has a lower cracking limit temperature $\left(3^{\circ} \mathrm{C}\right.$ vs. $\left.5^{\circ} \mathrm{C}\right)$.

- HMAC of type EME of class 2, can be obtained by a 50/70 bitumen modified with Selenizza or with a 50/70 bitumen and addition of Selenizza in the asphalt mix.

- TSRST, UTST results and the calculated values of the uniaxial strength reserve show that the LT performance of HMACs that contain Selenizza ${ }^{\circledR}$ is higher than that of the HMAC produced with 20/30 petroleum bitumen. The HMACs with asphaltite are more ductile and in the majority of the covered temperature range, present higher tensile strength and higher tensile strength reserve. In addition, the $T_{\text {failure }}$ determined by TSRST is $3.5-4.5^{\circ} \mathrm{C}$ lower for HMACs with Selenizza

So, these findings suggest that Selenizza can be used for the production of hard bitumens and of HMACs and can be an alternative to hard petroleum bitumens. 


\section{References}

[1] J.-F. Corté, "Development and uses of hard-grade asphalt and of high-modulus asphalt mixes in france," in Perpetual Bituminous Pavements, no. 503, TRC, Decembre 2001.

[2] H. Geng, C. S. Clopotel, and H. U. Bahia, "Effects of high modulus asphalt binders on performance of typical asphalt pavement structures," Construction and Building Materials, vol. 44, no. 0, pp. $207-213,2013$.

[3] A. I. . Eurobitume, The bitumen industry - A global perspective. Production, chemistry, use, specification and occupational exposure. Asphalt Institute Inc. \& European Bitumen Association-Eurobitume, 2011.

[4] B. Lombardi, "Les bitumes de grade dur et le 20/30." Bitume Info, August 2012.

[5] A. Bardesi, B. Brûlé, and J. françois Corté, "Use of modified bituminous binders, special bitumens and bitumens with additives in road pavements," tech. rep., Association mondiale de la route AIPCR, 1999.

[6] B. Huang and X. Shu, "Investigation into two procedures of applying gilsonite into hma mixtures," in Efficient Transportation and Pavement Systems, 2009.

[7] B. V. Kök, M. Yilmaz, and M. Guler, "Evaluation of high temperature performance of sbs + gilsonite modified binder," Fuel, vol. 90, pp. 3093-3099, 2011.

[8] Y. Y, "Polymer modified asphalt binders," Construction and Building Materials, vol. 21, pp. 67-72, 2007.

[9] S. Aflaki and N. Tabatabaee, "Proposals for modification of iranian bitumen to meet the climatic requirements of iran," Construction and Building Materials, vol. 23, p. 2141-2150, 2009.

[10] S. Aflaki, P. Hajikarimi, E. H. Fini, and B. Zada, "Comparing effects of biobinder with other asphalt modifiers on low-temperature characteristics of asphalt," Journal of Materials in Civil Engineering, vol. 26, no. 3, pp. 429-439, 2014.

[11] M. Ameri, A. Mansourian, S. S. Ashani, and G. Yadollahi, "Technical study on the iranian gilsonite as an additive for modification of asphalt binders used in pavement construction," Construction and Building Materials, vol. 25, no. 3, pp. 1379 - 1387, 2011.

[12] A. Themeli, Etude du potentiel d'emploi des bitumes naturels dans la production des liants bitumineux durs et des enrobés à module élevé. $\mathrm{PhD}$ thesis, Strasbourg University, 2015.

[13] A. Themeli, E. Chailleux, F. Farcas, C. Chazallon, B. Migault, and N. Buisson, "Molecular structure evolution of asphaltite-modified bitumens during ageing; comparisons with equivalent petroleum bitumens," International Journal of Pavement Research and Technology, vol. 10, no. 1, pp. 75 - 83, 2017. Selected Contributions to the RILEM SIB2015 Symposium.

[14] A. Themeli, E. Chailleux, F. Farcas, C. Chazallon, and B. Migault, "Molecular weight distribution of asphaltic paving binders from phase-angle measurements," Road Materials and Pavement Design, vol. 16, no. sup1, pp. 228-244, 2015.

[15] F. Migliori and J.-F. Corte, "Comparative study of rtfot and pav aging simulation laboratory tests," Transportation Research Record, vol. 1638, pp. 56-63, 1998.

[16] M. L. Guern, E. Chailleux, F. Farcas, S. Dreessen, and I. Mabille, "Physico-chemical analysis of five hard bitumens: Identification of chemical species and molecular organization before and after artificial aging," Fuel, vol. 89, no. 11, pp. 3330 - 3339, 2010.

[17] N. Lee and S. Hesp, "Low-temperature fracture toughness of polyethylene modified asphalt binders," Transportation Research record, vol. 1436, pp. 54-59, 1994. 
[18] G. R. Morrison, J. K. Lee, and S. A. M. Hesp, "Chlorinated polyolefins for asphalt binder modification,” Journal of Applied Polymer Science, vol. 54, no. 2, pp. 231-240, 1994.

[19] J. Ponniah and S. Hesp, "Use of fracture energy in performance-based specifications of asphalt binders," in Proceedings, Canadian Technical Asphalt Association, vol. 41, pp. 127144, 1996.

[20] E. Chailleux, D. Hamon, and V. Mouillet, "Determination of the low temperature bitumen cracking properties: Fracture mechanics principle applied to a three points bending test using a non homogeneous geometry," in 10th International Conference on Asphalt Pavements, vol. 1, (Québec), pp. 419-428, Août 2006.

[21] E. Chailleux, V. Mouillet, E. Scholten, T. Blomberg, and S. Dreessen, "Evaluation of the three point bending test as a tool to qualify the low temperature behaviour of bituminous binder," in Congrès Eurasphalt \& Eurobitume, (Copenhague, Danemark), pp. 21-28, Mai 2008.

[22] M. L. Guern, E. Chailleux, S. Dreessen, and F. Farcas, "Essai de flexion trois points sur barreau entaillé de bitume," in XXVIIIe Rencontres Universitaires de Génie Civil, Juin 2010.

[23] B. Huang, G. Li, and X. Shu, "Investigation into three-layered hma mixtures," Composites: Part B, vol. 37, pp. 679-690, 2006. 